\title{
Drug Related Problems of Diabetic Nephropathy Patients in a Tertiary Hospital in Malaysia
}

\author{
Dika P. Destiani, Athirah Ghazali
}

Department of Pharmacology and Clinical Pharmacy, Faculty of Pharmacy, Universitas Padjadjaran, Jatinangor, West Java, Indonesia

\begin{abstract}
Patients with diabetic nephropathy (DN) are particularly vulnerable to drug related problems (DRPs) due to complex medication regimen and renal dysfunction. However, there was limited information regarding prevalence of DRPs among patients with DN in Malaysia. This research was conducted to determine the prevalence of DRPs among hospitalized patients with DN at tertiary hospital in Malaysia during June 2014-May 2015. This was a retrospective observational descriptive study that used patients medical records as data source. There were 104 subjects included in this study. The prevalence of DRPs among the included subjects was $74 \%$. Most DRPs observed were from two categories, namely non-compliance to medication and adverse drug reactions (20.93\% for both categories). These categories were followed by the category of unnecessary drugs $(16.28 \%)$, too low dose $(15.81 \%)$, inappropriate drugs $(11.16 \%)$, untreated indication $(10.23 \%)$ and too high dose $(4.65 \%)$. The prevalence of DRP was high among DN patients, thus pharmacists are encouraged to perform comprehensive medication review to improve health outcomes and enhance patients safety.
\end{abstract}

Keywords: drug related problems, diabetic nephropathy, T2DM

\section{Introduction}

Type 2 diabetes mellitus (T2DM) is a metabolic disorder characterized by hyperglycemia caused by either a lack of insulin or the body's inability to use insulin efficiently. The chronic hyperglycemia is associated with long-term damage and dysfunction of various organs. ${ }^{1,2}$ T2DM increases the risk of microvascular complication, such as diabetic nephropathy $(\mathrm{DN}){ }^{3}$

Diabetic nephropathy (DN) is a major cause of chronic kidney disease and end-stage renal failure worldwide. Its clinical syndromes include the presence of pathological quantities of urine albumin excretion, diabetic glomerular lesions, and loss of glomerular filtration rate (GFR) in diabetics. Poor control of blood gluce is one of the risk factors of DN. ${ }^{4,5}$

Patients with DN often receive complex medication regimen. This condition may increase the risk of drug related problems (DRPs) among DN patients. DRPs represent

Corresponding author: Dika P. Destiani. Department of Pharmacology and Clinical Pharmacy, Faculty of Pharmacy, Universitas Padjadjaran, Jatinangor, West Java, Indonesia. Email: dika.pramita@unpad.ac.id

Received: 13 May 2016. Revised: 24 June 2016. Published: 1 August 2016 
the categorization of clinical problems related to the use of medications, including inappropriate drugs, non-compliance, adverse drug reaction (ADR), etc. ${ }^{6-10}$

However, there was limited information regarding the prevalence of DRPs among DN patients in Malaysia. This study was conducted to investigate the prevalence of DRPs and the most common DRPs categories in hospitalized DN patients in a tertiary hospital in Malaysia.

\section{Methods}

This retrospective study involved hospitalized DN patients at a tertiary hospital in Malaysia from June 2014 to May 2015. The data source was the medical records of the patients. We included DN patients whose age $\geq 18$ years old and those who received at least two drugs for the treatment of DN. The exclusion criteria was incomplete patient data

From each record, the following data were extracted; medical prescriptions and patient data, i.e., name, age, sex, duration of illness, duration of treatment, the results of treatment, diagnosis, number of drug doses, type of drug administered, concomitant drugs, and laboratory tests data. The data obtained were transferred and summarized in data collection sheet.

DRPs were further analyzed using standard literature of appropriate drug use such as the British National Formulary, Monthly Index of Medical Specialities, Drug Information Handbook and Drug Interaction Facts.

\section{Results and Discussion}

104 participants were included in this study. Data regarding patient profile and DRPs were obtained.

\section{Patient profile}

The number of female patients was dominant compared to the male patients (61\%). Previous study showed that both men and women had the same prevalence and risk of DN. ${ }^{11}$ Most patients were in the age of 45 to 64 years $(61 \%)$. American Diabetes Association (ADA) stated that one of the risk factor in developing complication among T2DM patients is $\geq 45$ years old. ${ }^{2}$ The average duration of hospitalization was 1-3 days which was related to the effectiveness of treatment and comorbidities. About 54\% of the patients had improved condition when discharged from the hospital. $45 \%$ of the patients have been diagnosed with T2DM for 11-15 years. Duration of disease was related to the development of complication. ${ }^{5}$

The most widely use antidiabetic drugs was insulin group. Insulin is the most appropriate drug therapy for DN patients. ${ }^{12}$ The use of metformin should be given in a controlled

Table 1. Total of DRPs among patients with DN

\begin{tabular}{llcc}
\hline No & Classification of DRPs & Frequency & Percentage (\%) \\
\hline 1 & Untreated indication & 22 & 10.23 \\
2 & Unnecessary drug & 35 & 16.28 \\
3 & Inappropriate drug & 24 & 11.16 \\
4 & Too high dose & 10 & 4.65 \\
5 & Tow low dose & 34 & 15.81 \\
6 & Non-compliance to medication & 45 & 20.93 \\
7 & ADR & 45 & 20.93 \\
\hline & Total & 215 & 100 \\
\hline
\end{tabular}


Table 2. Causes of DRPs in the category of inappropriate drugs

\begin{tabular}{clc}
\hline No & \multicolumn{1}{c}{ Causes of DRPs } & Frequency \\
\hline 1 & Drugs given were not the most effective drugs & 13 \\
2 & Drugs given were effective, but not safe & 9 \\
3 & Drugs given were right, but inappropriate for patient's condition & 4 \\
\hline & Total & 26 \\
\hline
\end{tabular}

dosage. ${ }^{13}$ The most commonly used drugs to control DN was Angiotensin II Receptor Blocker (ARB) and angiotensin-converting enzyme inhibitor (ACEI). Previous studies showed that ARB triggers favorable changes in systemic blood pressure, renal hemodynamics, and proteinuria similar to those induced by ACEI. The combination of ARB and ACE inhibition is safe and more effective than monotherapy to reduce systemic blood pressure and albuminuria in DN. ${ }^{14}$

\section{DRPS}

The prevalence of DRPs was $77 \%$. The most common DRPs experienced by patients were non-compliance to medication and adverse drug reaction (ADR), in which 45 cases $(20.93 \%)$ were observed in both categories respectively. The other DRPs observed included untreated indication (10.23\%), unneeded drug (16.28\%), inappropriate drug $(11.16 \%)$, too high dose (4.65\%), and too low dose $(15.81 \%)$. (Table 1$)$

\section{Untreated indication}

17 patients had symptoms of health problem with no drugs were given to address such issue. For example, the patient had a fever but an antipyretic was not prescribed. In other 15 cases, patients were not given additional medication for the prevention of side effects that arise when taking medication.

\section{Unnecessary drugs}

The main cause of such cases were due to redundant effects from duplication of treatment whose mechanism of actions were similar (22 cases). Another cause was the administration of drugs without indication (13 cases).

Table 3. Group of drugs that caused DRPs in the category of too low dose

\begin{tabular}{clcc}
\hline No & & Group of Drugs & Frequency \\
\hline 1 & Antidiabetic drugs: & \\
& Biguanide & 11 \\
& Sulphonylurea & 2 \\
& Subtotal & 13 \\
\hline 2 & DN drugs: & \\
& ACEI & & 10 \\
& ARB & & 7 \\
& Calcium channel blocker & 3 \\
& Diuretic & & 1 \\
& Subtotal & Total & 21 \\
\hline & & & 34 \\
\hline
\end{tabular}


Table 4. Class of drugs that caused ADR

\begin{tabular}{lcc}
\hline \multicolumn{1}{c}{ Class of Drugs } & Frequency & \% \\
\hline ACEI & 10 & 43.48 \\
Antidiabetic & 6 & 26.10 \\
Calcium channel blocker & 4 & 17.39 \\
Diuretic & 3 & 13.03 \\
Total & 23 & 100 \\
\hline
\end{tabular}

Inappropriate drugs

There were three main causes of inappropriate drugs given in this study. First, patients received the drug but not the most effective. For example, metoprolol, a beta blocker, was given to patients. However, the more appropriate drug for DN patients was ACEI, such as perindropil. Previous study showed that ACEI could reduce the symptoms of albuminuria with a higher percentage from beta blocker. ${ }^{15}$ Second, the patients received the drugs that were effective, but not safe. Gliclazide was not appropriate for patients who had renal impairment. ${ }^{16}$ Third, the patients received the right type of drug, but it was inapproriate for patients condition. Irbesartan $300 \mathrm{mg}$ can only be used in T2DM patients who had a serum creatinine $>300$ $\mathrm{mg} / \mathrm{ml} .{ }^{17}$ (Table 3)

Too low dose

The most frequent DRPs in this category came from biguanide group. Metformin should be given in a dose of $500 \mathrm{mg}$, but it was given in a dose of $250 \mathrm{mg}$ twice daily. Irbersartan, an ACEI, was prescribed with a dose of $150 \mathrm{mg} 1 \mathrm{x} /$ day which is not sufficient because the required dose for nephropatic complication is $300 \mathrm{mg} \mathrm{1x} /$ day. $^{17}$ (Table 4)

\section{Too high dose}

Glicazide was often given in the dose of 160 $\mathrm{mg} 1 \mathrm{x} /$ day, while the appropriate dose for DN patients was $80 \mathrm{mg} \mathrm{1x/day.}{ }^{18}$ (Table 5)
Patient compliance to medication is necessary to achieve the optimum therapeutic effect. Non-compliance could be resulted from the administration of too many combinations of drugs and inconvenience frequency and dosing. Besides, error in taking medication was also one of the causes of the noncompliance. It was found that most patients stored drugs in wrong and incompatible container for example Telmisartan $80 \mathrm{mg}$ medication stored in the Ranitidine $150 \mathrm{mg}$ container. Poor adherence was associated with development of complications. ${ }^{19,20}$

\section{$A D R$}

We found that most frequent ADR observed were associated with the use of ACEI, such as dry cough and hyperkalemia. Hypoglicemia was also one of the side effects of antidiabetic drugs that was frequently reported by patients (Table 4). Drug interactions occur when one drug alters the pharmacological effect of another drug. The pharmacological effect of one or both drugs may be increased or decreased, or a new and unanticipated toxicity may be produced. Increased toxicity can be resulted from pharmacodynamic or pharmacokinetics interaction. ${ }^{21-24}$

\section{Conclusion}

The prevalence of DRP was high among DN patients, thus pharmacists are encouraged to perform comprehensive medication review to improve health outcomes and enhance patients safety. 


\section{Acknowledgement}

None.

\section{Funding}

None.

\section{Conflict of Interest}

None declared.

\section{References}

1. American Diabetes Association. Diagnosis and Classification of Diabetes Mellitus. Diabetes Care. 2010;33(Suppl 1):S62-S69.

2. Mafauzy M, Hussein Z, Chan S. The status of diabetes control in Malaysia. Medical Journal of Malaysia. 2011;66(3):175181.

3. Chawla A, Chawla R, Jaggi S. Microvasular and macrovascular complications in diabetes mellitus. Indian Journal of Endocrinology and Metabolism. 2016;20(4):546-551.

4. Lim AK. Diabetic nephropathy: complications and treatment. International Journal of Nephrology and Renovascular Disease. 2014;7:361-381.

5. Fineberg D, Jandeleit-Dahm KA, Cooper ME. Diabetic nephropathy: diagnosis and treatment. Nature Review Endocrinology. 2013;9:713-723.

6. Kanakamani J, Ammini AC, Gupta $\mathrm{N}$, Dwivedi SN. Prevalence of microalbuminuria among patients with type 2 diabetes mellitus: a hospitalbased study from North India. Diabetes Technology and Therapy. 2010;12:161166.

7. Van Roozendaal BW, Krass I. Development of an evidence-based checklist for the detection of drug related problems in type 2 diabetes. Pharmacy World \& Science. 2009;31(5):580-595.

8. Zaman Huri H, Chai Ling L. Drug-related problems in type 2 diabetes mellitus patients with dyslipidemia. BMC Public Health. 2013;13:1192-1198.

9. Ayalew MB, Megersa TN, Mengistu YT. Drug-related problems in medical wards of Tikur Anbessa specialized hospital, Ethiopia. Journal of Research in Pharmacy Practice. 2015;4(4):216-221.

10. Gnudi L. Molecular mechanisms of proteinuria in diabetes. Biochemical Society Transactions. 2008;36:946-949.

11. Schreiber AK, Nones CF, Reis RC, Chichorro JG, Cunha JM. Diabetic neuropathic pain: Physiopathology and treatment. World Journal of Diabetes. 2015;6(3):432-444.

12. Kautzky-Willer A, Harreiter J, Pacini G. Sex and gender differences in risk, pathophysiology and complications of type 2 diabetes mellitus. Endocrine Reviews.201;37(3):278-316.

13. Weir MR. Effects of renin-angiotensin system inhibition on end-organ protection. Clinical Therapeutics. 2007;29:18031824

14. Lipska KJ, Bailey CJ, Inzucchi SE. Use of metformin in the setting of mild-tomoderate renal insufficiency. Diabetes Care. 2011;34:1431-1437.

15. Fernyhough P.Mitochondrialdysfunction in diabetic neuropathy: a series of unfortunate metabolic events. Current Diabetes Repository. 2015;15:89.

16. Cao Z, Cooper ME. Pathogenesis of diabetic nephropathy. Journal of Diabetes Investigation. 2011;2(4):243-247.

17. RXlist, 2014. Irbesartan dosage. Available at http//rxlist.com. [Accessed on 21 February 2016].

18. Medical management information system (MIMS). 2016. Gliclazide. Available at http//www.mims.com. [Accessed on 21 Februari 2016]

19. Polonsky WH, Henry RR. Poor medication adherence in type 2 diabetes: recognizing the scope of the problem and 
its key contributors. Patient Preference and Adherence. 2016;10:1299-1307.

20. Cramer JA, Benedict Á, Muszbek N, Keskinaslan A, Khan ZM. The significance of compliance and persistence in the treatment of diabetes, hypertension and dyslipidaemia: a review. International Journal of Clinical Practice. 2008;62(1):76-87.

21. May M, Schindler C. Clinically and pharmacologically relevant interactions of antidiabetic drugs. Therapeutic Advances in Endocrinology and Metabolism. 2016;7(2):69-83.

22. PinargoteP, Guillen D, Guarderas JC. ACE inhibitors: upper respiratory symptoms. BMJ Case Reports. 2014;2014:205-262.

23. Becker DE. Adverse drug interactions. Anesthesia Progress. 2011;58(1):31-41.

24. Ansari J. Drug interaction and pharmacist. Journal of Young Pharmacists. 2010;2(3):326-331. 


\title{
Antioxidant Activity of Ethanol Extract of Polygonum pulchrum Blume
}

\author{
Asman Sadino ${ }^{1}$, Idin Sahidin ${ }^{1}$, Wahyuni Wahyuni²
}

${ }^{1}$ Department of Natural Products Chemistry, Faculty of Pharmacy, Halu Oleo University, Kendari, South East Sulawesi, Indonesia

${ }^{2}$ Department of Pharmacology and Toxicology, Faculty of Pharmacy, Halu Oleo University, Kendari, South East Sulawesi, Indonesia

\begin{abstract}
The use of antioxidants from natural resources has attracted increasing interest. One of the plant that was empirically used as an antioxidant dietary supplement was Polygonum pulchrum Blume ( $P$. pulchrum Blume). This study aimed to investigate antioxidant activity of roots, stems, leaves and flowers ethanol extract of $P$. pulchrum Blume. The extract was obtained by maceration method using ethanol solvent. Antioxidant activity was determined with 1,1-diphenyl-picrylhydrazyl (DPPH) method. We found that ethanol extracts of P. pulchrum Blume roots and stems had strong antioxidant activity with $\mathrm{IC}_{50}$ values of $25.2 \mathrm{mg} / \mathrm{l}$ and $43.26 \mathrm{mg} / 1$, respectively. Ethanol extract of flowers had the weakest antioxidant activity with $\mathrm{IC}_{50}$ value of $202.96 \mathrm{mg} / \mathrm{l}$. Vitamin $\mathrm{C}$ had very strong antioxidant activity with $\mathrm{IC}_{50}$ value of $3.97 \mathrm{mg} / \mathrm{l}$. In conclusion, this study revealed that ethanol extract of $P$. pulchrum Blume roots and stems had strong antioxidant activity, therefore, this plant might be potential as an excellent source for natural antioxidant agents for medical application.
\end{abstract}

Keywords: Polygonum pulchrum Blume, DPPH, antioxidant, maceration, ethanol

\section{Introduction}

The use of antioxidants derived from plants have widely improved around the world. Many plants contain various phytochemicals which possess antioxidant activity to protect cells from damaging effects of reactive oxygen species (ROS), such as superoxides, peroxyl radicals, hydroxyl radicals and peroxinitrins. $^{1,2}$
In human, production of ROS as the result of biochemical process might increase with several factors, including toxins and chemicals in food, pollutants, radiations, etc. Antioxidants compounds are needed to tackle this problem. However, synthetic antioxidant compounds such as butylated hydroxytoluene and hydroxyanisole might cause various side effects. ${ }^{3}$ This encourage researchers to find

Corresponding author: Asman Sadino, Department of Natural Products Chemistry, Faculty of Pharmacy, Halu Oleo Univer-

sity, Kendari, South East Sulawesi, Indonesia. Email: asmansadino51@gmail.com

Received: 20 May 2016. Revised: 8 July 2016. Published: 1 August 2016 